\title{
26. Introduction
}

\section{A. Markandya and N. Dale}

\section{THE URBAN ENVIRONMENTAL PROBLEMS POLICY FIELD}

The urban environment is both the source of a wide array of interrelated environmental pressures and the principal location of many environmental impacts. There are also great differences in environmental conditions and economic activities between urban areas across regions and countries. For these reasons the Urban Environmental Problems policy field is perhaps the most difficult to define. Furthermore, it is difficult to achieve a balanced set of indicators that adequately represent the many dimensions of the problems of this policy area.

In the first-round questionnaire the complexity of pressures on the urban environment was illustrated by the range of suggestions for pressure indicators that were received. These suggestions were screened for specific relevance and the number of experts who proposed them, to arrive at a list of 30 indicators for the second-round questionnaire. ${ }^{1}$ These were arranged in 15 categories including indicators for land use (total built-up area, derelict area), urban air emissions $\left(\mathrm{SO}_{2}, \mathrm{NO}_{\mathrm{x}}, \mathrm{VOC}, \mathrm{PM}_{10}\right)$, water (water consumption per capita), waste (municipal waste by type), energy (energy consumption by uses and sources), mobility (registered motor vehicles), noise (people exposed to noise) and health (incidence of asthma).

\section{RESULTS OF THE SECOND-ROUND QUESTIONNAIRE}

Figure 26.1 shows the results of the second-round questionnaire for Urban Environmental Problems for the three quality questions and the core-ranking question (given as a percentage of experts including the indicator in their top five core ranking).

The top five rankings for these four questions were as follows: 


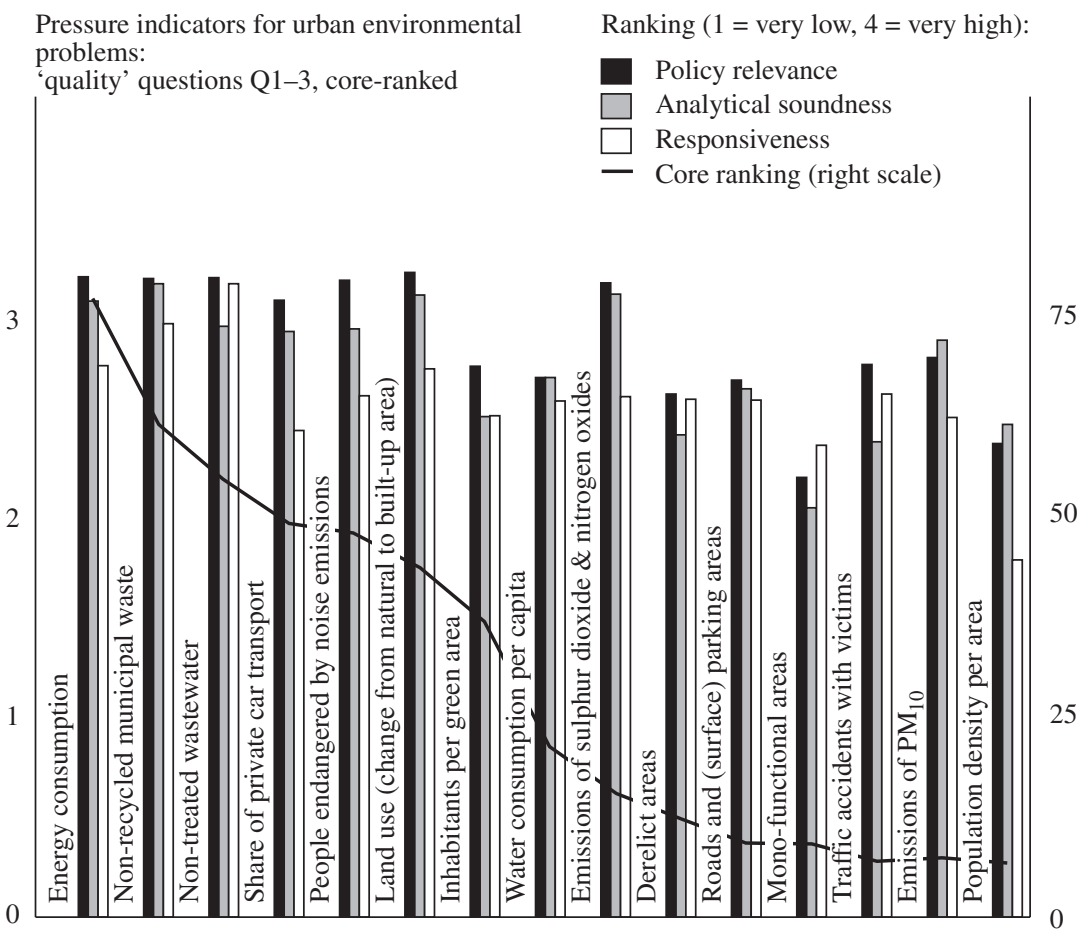

Figure 26.1 Results of second-round questionnaire for the Urban Environmental Problems policy field

- Core-ranked indicators: energy consumption, non-recycled municipal waste, non-treated wastewater, share of private car transport, people endangered by noise emissions.

- Policy relevance indicators: land use (change from natural to built-up area), energy consumption, non-treated wastewater, people endangered by noise emissions, non-recycled municipal waste.

- Analytical soundness indicators: non-recycled municipal waste, land use (change from natural to built-up area), emissions of $\mathrm{SO}_{2}$ and $\mathrm{NO}_{\mathrm{x}}$, energy consumption, non-treated wastewater.

- Response elasticity indicators: non-treated wastewater, non-recycled municipal waste, energy consumption, land use (change from natural to built-up area), traffic accidents with victims.

Despite the diverse nature of the lists of proposed indicators presented to respondents, there is general agreement between the top five rankings for the 
four questions with indicators for energy consumption, non-treated wastewater, and non-recycled municipal waste featuring in all four of the top five rankings. The land-use indicator features in three of the top five rankings. Further down the rankings there is less agreement between the four questions. Further details and discussion of these results can be found in the TEPI publication on Indicator Definition. ${ }^{2}$

\section{RELATIONS TO OTHER POLICY FIELDS}

The Urban Environmental Problems policy field has complex links to most of the other policy fields since it is defined by the physical environment, while most are defined by environmental media, such as air and water, or specific issues, such as climate change and ozone depletion. This has resulted in a set of proposed indicators that cut across related policy fields, principally Waste, Air Pollution and Water, but are also central to the Urban Environmental Problems policy field.

The indicator for non-recycled municipal waste features highly in the questionnaire rankings, thus illustrating the clear linkage to the Waste policy field. However, in the Waste policy field the pressures are measured on a national basis.

Links to the Water policy field are evidenced by the high ranking of nontreated wastewater and water consumption per capita as Urban Environmental Problem indicators.

Air Pollution is closely associated with Urban Environmental Problems, in particular in relation to a variety of adverse health effects. The 'conventional' air pollutants, sulphur dioxide, black smoke and lead, were largely connected with urban combustion of fossil fuel. In recent years a new class of air pollutants, which includes nitrogen dioxide and ozone, has appeared. These are related to road transport and are especially evident in many urban atmospheres. Therefore, indicators such as share of private car transport and emissions of $\mathrm{SO}_{2}$ and $\mathrm{NO}_{\mathrm{x}}$ are strongly related to Air Pollution. The effects of acidification also fall within the Urban Environmental Problems policy field since severe damage has been caused to historical buildings and monuments that constitute part of the cultural heritage in European cities.

\section{APPROACH USED IN THE CONTRIBUTION}

The chapter by Professor Fudge takes a broad interdisciplinary approach to the task of analysing urban problems and recommending actions to reduce environmental pressures. While examining the issues at European Union 
level, he recognizes that wider European and global environmental, economic and social processes should also inform the discussion.

The problems faced by European cities are set in the context of rapid global and European urbanization, with recent statistics indicating that the EU is around 79 per cent urbanized. The major urban problems in Europe are grouped under the nine themes of: social exclusion, lifestyle and equity; degradation of the urban environment; transportation and accessibility; the need for new forms of institutional capacity and governance; technological management: waste, water, air and resource use; urban dereliction and redundant buildings; urban economic uncertainty and unemployment; crime and personal safety; and leisure and tourism impacts.

In his recommendations for action to reduce the problem of environmental pressures Professor Fudge refers to the detailed recommendations of the European Sustainable Cities Report (CEC, 1996), drawn up by the European Commission's Expert Group on the Urban Environment. This report presents an integrated set of policies which 'draw on the inter-relationship of the substance of problems and the processes that create them', recommending a wide agenda of actions for the sustainable management of natural resources, covering air quality, soil, flora and fauna, water, energy conservation and waste management. The problem areas related to air, water, energy and waste correspond to the area covered by most of the highly ranked pressure indicators. The report also identifies actions for sustainability in the socio-economic context, at the levels of Member State governments and regional and local authorities, and for social sustainability.

The chapter also stresses the need for action to achieve sustainable urban accessibility as a vital step in the improvement of the urban environment. Professor Fudge draws on The Future Development of the Common Transport Policy (CEC, 1992) as a useful policy framework for issues of mobility and access. In conclusion, the importance of spatial planning systems as a basis for sustainable urban development is outlined. Recommendations are made for the development of land-use policy and practice based on those produced by the Expert Group on the Urban Environment (see above paragraph).

\section{INTERNATIONAL FRAMEWORK}

The complex and broad-based definition of urban environmental problems means that it is difficult to reach simple and clearly defined goals for international agreement as was the case with, for example, ozone depletion. However, there have been several international initiatives for sustainable cities, which are outlined below: 
- As a result of the need to implement the Local Agenda 21 (chapter 28) of the 1992 United Nations Conference on Environment and Development, the Local Agenda 21 Initiative was established by the International Council of Local Environmental Initiative (ICLEI) and the International Union of Local Authorities (IULA). It aims to develop a planning framework for local sustainable development focusing on actions such as consultation, audits, target setting and monitoring.

- The Sustainable Cities Project was set up by the European Commission's Expert Group on the Urban Environment in 1993. Their report, referred to in Professor Fudge's chapter, sets out recommendations for integrating urban environmental issues into EU, national and local policies. The project has also launched a Sustainable City Network for the exchange of information and experience.

- The OECD Environmental Group on Urban Affairs established the Ecological City Project in 1993 to identify integrated national strategies for urban environmental problems. This project has concentrated on issues such as urban renewal and redevelopment, transport infrastructures and energy consumption.

- The Healthy Cities Project is a global initiative set up by the World Health Organization (WHO) in 1991 working for the introduction of programmes for improving the urban environment and health. Under this project health-related environmental indicators are being developed.

- A further international significant initiative is the European Charter for Sustainable Cities and Towns, launched at the European Conference on Sustainable Cities in Aalborg in 1994.

\section{NOTES}

1. First questionnaire: December 1995; second questionnaire: October 1996. See Editors' introduction.

2. See Foreword.

\section{REFERENCES}

CEC (1992), The Future Development of the Common Transport Policy: a global approach to the construction of a Community framework for sustainable mobility (Luxembourg: CEC).

CEC (1996), European Sustainable Cities Report, Expert Group on the Urban Environment (Luxembourg: CEC). 